\title{
O fomento à pesquisa em Zootecnia pelo CNPq: Editais Universais
}

\author{
Roberto Camargos Antunes ${ }^{1}$, Emerson Silva Ribeiro Júnior ${ }^{1}$, Onivaldo Randig ${ }^{1}$, Maria \\ Auxiliadora da Silveira e Pereira Neves ${ }^{1}$, Cláudia Queiroz Gorgati ${ }^{1}$, Leila de Souza Lynch $^{1}$ \\ ${ }^{1}$ Conselho Nacional de Desenvolvimento Científico e Tecnológico - CNPq. Coordenação do Programa de Pesquisa em Agropecuária e do \\ Agronegócio. SEPN 509, Bloco A, Edifício Nazir I, Asa Norte, CEP: 70.750-501, Brasília/DF.
}

RESUMO - Objetivou-se avaliar e divulgar a evolução da demanda bruta e da demanda atendida de projetos de pesquisa nos Editais Universais 01/2002, 019/2004 e 02/2006 das subáreas do conhecimento que constituem o Programa Básico de Zootecnia do CNPq (Ecologia dos animais domésticos e etologia; Genética e melhoramento dos animais domésticos; Nutrição e alimentação animal; Pastagem e forragicultura; e Produção animal) para evidenciar a distribuição regional dessas demandas. Os dados foram obtidos por meio de consultas aos bancos de dados Oracle ${ }^{\circledR}$ do CNPq utilizando-se a ferramenta de busca PL-SQL, pela Coordenação de Suporte ao Fomento - COSFO. Das 809 solicitações de financiamento em todas as subáreas do Programa Básico de Zootecnia no período, foram financiadas 168 propostas (20,8\% do total). Nutrição e alimentação animal, Pastagem e forragicultura e Produção animal foram as três subáreas com maior demanda por recursos financeiros. A Região que apresentou maior demanda bruta nos três Editais foi a Sudeste (46,7\% do total), com R\$ 14,2 milhões, seguida pela Região Sul (18,4\% do total). O CNPq tem aprimorado os mecanismos de fomento à pesquisa científica e tecnológica brasileiras como forma de aumentar o aporte de recursos financeiros disponibilizados aos pesquisadores atuantes no País.

Palavras-chave: ciência e tecnologia, desigualdades regionais, investimento público, transparência pública

\section{Public investment in the Animal Sciences research by CNPq: Universal Calls}

\begin{abstract}
The aim of this paper was to evaluate and to publish the study on the evolution of the relation between the total amount of submitted proposals and the supported ones, into the National Council for Scientific and Technological Development (CNPq)'s Animal Science Support Program subareas. The study was based on data from the last three Universal Calls (01/2002, 019/2004, and 02/2006) and evinced regional distribution of such variables. Data were obtained through CNPq's Oracle ${ }^{\circledR}$ database, using PL-SQL search tool. From a total of 809 submitted proposals, comprising all subareas of the Animal Science Support Program, 168 proposals were supported (20.8\%). Animal Nutrition followed by Pasture and Forage Crops and Animal Production Science were the subareas with the highest demand for financial supports. Southeast Region was the one with the higher submitted demand through the three calls, comprising $46.7 \%$ of total demand, what corresponds to R\$ 14.2 millions, followed by South Region, which represented 18,4\% of total demand. There had been no limits for CNPq efforts in order to improve fomentation mechanisms for Brazilian scientific and technological research and to increase available financial resources to Brazilian researchers.
\end{abstract}

Key Words: public support, public transparency, regional disparity, science and technology

\section{Introdução}

Estudos comprovam existir forte correlação entre a fração do PIB investido em ciência e tecnologia (C\&T) por um país e seu desenvolvimento geral. Essa fração varia de 2,6\%, países mais desenvolvidos, a 0,1\%, países menos desenvolvidos (Kuppermann, 1994). A intensidade desse investimento certamente reflete no número de publicações e citações internacionais, índices que evidenciam a intensidade da produção científica e tecnológica dos diferentes países. Segundo dados do Thomson Institute for Scientific Information (Thomson ISI), catalogados por King (2004), durante os anos de 1997 a 2001, os Estados Unidos tiveram 1.266.808 publicações entre as mais citadas, e foram seguidos pelo Reino Unido, com 342.535 publicações, e pela Alemanha, com 318.286 publicações. O Brasil teve nesse período 43.971 publicações entre as mais citadas e destacou-se em $18^{0}$ lugar em produção de artigos científicos internacionais mais citados.

Segundo dados do Ministério da Ciência e Tecnologia (Ministério, 2005), o investimento total do Governo Federal em ciência, tecnologia e inovação (C,T\&I ) - incluindo os 
ministérios, as empresas estatais e instituições vinculadas - alcançou R\$ 14,5 bilhões em 2005. Juntamente com o setor privado, os investimentos nacionais totais em C,T\&I atingiram naquele ano $\mathrm{R} \$ 26,4$ bilhões, um investimento de $1,37 \%$ do PIB. Nota-se que o investimento em C,T\&I pelo Brasil encontra-se muito aquém daquele dos países desenvolvidos, o que torna imprescindível a intensificação do investimento pelos governos federal e estadual e pelo setor privado para que o País alcance níveis de desenvolvimento sustentável.

O Conselho Nacional de Desenvolvimento Científico e Tecnológico (CNPq), fundação pública de direito privado vinculada ao Ministério da Ciência e Tecnologia (MCT), uma das maiores e mais sólidas estruturas públicas de apoio à ciência, tecnologia e inovação, constitui referência para os países em desenvolvimento e executou orçamento de R 908 milhões em 2006. Por meio de suas ações de fomento, o CNPq estimula a formação de recursos humanos para a pesquisa (mestres, doutores e especialistas nas diversas áreas de conhecimento) com a concessão de bolsas, o financiamento de projetos de pesquisa científica, tecnológica e de inovação em todas as áreas do conhecimento e com a concessão de auxílios por meio de Editais.

Entre as diversas modalidades de fomento à pesquisa oferecidas pelo CNPq aos pesquisadores atuantes no País, o Edital Universal é uma das mais importantes, pois representa a demanda espontânea pela pesquisa das Universidades e dos Centros de Pesquisa, uma vez que é aberto aos pesquisadores doutores e a pesquisas de todas as áreas do conhecimento. O Edital Universal foi criado com o objetivo de financiar a execução de projetos apresentados por pesquisadores com contribuição significativa ao desenvolvimento científico e tecnológico do País.

A Coordenação Geral do Programa de Pesquisa em Agropecuária e Biotecnologia - CGAPB - é uma das três coordenações gerais vinculadas à Diretoria de Programas Temáticos e Setoriais do CNPq. A CGAPB é composta por duas Coordenações Técnicas: a Coordenação do Programa de Pesquisa em Biotecnologia e Recursos Genéticos COBRG - e a Coordenação do Programa de Pesquisa em Agropecuária e Agronegócio-COAGR. A COAGR reúne sete programas científicos básicos (Agronomia, Aqüicultura e Recursos Pesqueiros, Ciência e Tecnologia de Alimentos, Engenharia Agrícola, Medicina Veterinária, Recursos Florestais e Engenharia Florestal e Zootecnia), que estão inseridos dentro da área do conhecimento de Ciências Agrárias.
Este estudo foi realizado com os objetivos de avaliar e divulgar a evolução da demanda bruta (total de propostas apresentadas) e da demanda atendida (total de propostas financiadas) nos Editais Universais 01/2002, 019/2004 e 02/2006 das subáreas do conhecimento que constituem o Programa Básico de Zootecnia do CNPq para evidenciar a distribuição regional dessas demandas.

\section{Material e Métodos}

Os dados consolidados de demandas bruta e atendida nos Editais Universais 01/2002, 019/2004 e 02/2006 do Programa Básico de Zootecnia foram obtidos por meio de consultas aos bancos de dados Oracle ${ }^{\circledR}$ do CNPq, utilizando-se a ferramenta de busca PL-SQL, pela Coordenação de Suporte ao Fomento (COSFO) e disponibilizados em formato .xls (Excel) à Coordenação do Programa de Pesquisa em Agropecuária e do Agronegócio - COAGR.

O Programa Básico de Zootecnia do CNPq é constituído de cinco subáreas do conhecimento: a) Ecologia dos animais domésticos e etologia; b) Genética e melhoramento dos animais domésticos; c) Nutrição e alimentação animal; d) Pastagem e forragicultura; e e) Produção animal. Cada Programa Básico possui um Comitê Assessor correspondente, formado por pesquisadores de notória distinção científica junto à Comunidade Científica. O Comitê Assessor de Zootecnia (CA-ZT), composto por quatro membros titulares e um membro suplente, eleitos pelo Conselho Deliberativo do CNPq para um mandato de três anos, não prorrogáveis, é o responsável pela análise do mérito científico das propostas encaminhadas ao Programa Básico de Zootecnia e também pela recomendação dessas propostas à Diretoria do CNPq. Compete à Diretoria a decisão final sobre as concessões dos recursos financeiros disponíveis.

Os dados foram sistematizados por subárea do conhecimento da proposta e por região geográfica de execução do projeto, tanto em número de propostas quanto em valores (R\$). Os valores foram os originalmente solicitados e aprovados, sem correções por índices de inflação. Os dados das demandas bruta e atendida foram utilizados na elaboração do Índice Nacional de Aprovação (INA) e do Índice Regional de Aprovação (IRA), calculados por meio das seguintes equações:

INA $=n .{ }^{\circ}$ de propostas aprovadas no País $/ n .{ }^{\circ}$ de propostas apresentadas no País

IRA $=n .^{\circ}$ de propostas aprovadas na Região $/ n .{ }^{\circ}$ de propostas apresentadas na Região. 


\section{Resultados e Discussão}

A divisão em faixas de valores foi realizada visando à racionalização orçamentária dos projetos para aumentar a chance de financiamento a pesquisadores com produção científica, tecnológica ou em inovação ainda não consolidada, que normalmente tenderiam a solicitar volume menor de recursos por proposta em comparação àqueles mais produtivos (Tabela 1). Nos dois Editais Universais seguintes (1/2004 e 2/2006), não se utilizou essa estratégia e o valor total da proposta foi limitado a R $\$ 50$ mil. No entanto, como uma política afirmativa, visando o desenvolvimento regional, o edital de 2006 delimitou em seu item 1.4.3 que uma parcela mínima de $30 \%$ dos recursos deveria ser destinada a projetos desenvolvidos por pesquisadores vinculados a instituições sediadas no Norte, Nordeste ou Centro-Oeste, segundo determinação política dos Fundos Setoriais. Em 2007, o CNPq retomou a divisão por faixas e destinou recursos de aproximadamente $\mathrm{R} \$ 100$ milhões para os anos de 2007 e 2008 e manteve a política de desenvolvimento regional.

Somente nos três Editais Universais em estudo foram alocados R\$ 162 milhões à pesquisa e financiados 8.152 projetos em todas as áreas do conhecimento, o que resultou em demanda bruta estimada de 50.000 projetos, totalizando 1 bilhão de reais.

Os recursos financeiros do orçamento do $\mathrm{CNPq}$, disponibilizados anualmente pelo Tesouro Nacional, segundo o relatório institucional de gestão deste Conselho para os anos de 2003 a 2006, foram destinados à formação de recursos humanos (bolsas), $60 \%$ do total; adicional e taxa de bancada (fomento para bolsistas de doutorado e produtividade em pesquisa), 12,5\%; administração, 3\%; pessoal ativo, 6\%; e aposentados e inativos, 3,5\%. Para fomento à pesquisa (projetos de pesquisa), foram destinados anualmente em torno de $15 \%$ dos recursos do Plano Plurianual (PPA) disponibilizados para o CNPq e desses 15\% aproximadamente metade foi investida no Edital Universal, o que confirma sua importância como instrumento de apoio à pesquisa.

Nos Editais Universais em estudo, foram adotadas condutas substancialmente diferentes na aprovação do orçamento da proposta. No Edital 01/2002, não foram previstos cortes, ou seja, se a proposta foi meritória e se houve disponibilidade orçamentária do CNPq para esse Edital, a proposta foi aprovada com orçamento integral. No Edital 019/2004, no entanto, permitiu-se aos comitês assessores, adotando critérios próprios ou sugestão da área técnica e dos consultores ad hoc, readequar, sem limite de cortes, o orçamento proposto pelo pesquisador. Essa estratégia adotada no Edital 019/2004 pode, por vezes, ter inviabilizado a realização integral do projeto aprovado como formulado pelo pesquisador, em razão das dificuldades causadas por eventuais cortes excessivos. Reconhecendo essa possível distorção, o CNPq introduziu cláusula no Edital Universal 02/2006, que determinou o corte máximo de $30 \%$ sobre o valor solicitado no orçamento do projeto. Se o corte sugerido foi superior a este percentual, o projeto, embora tecnicamente meritório, foi automaticamente desclassificado do julgamento pelo Comitê Assessor. No Edital Universal 015/2007, o corte orçamentário dos projetos não pôde ultrapassar $20 \%$ do valor solicitado ao CNPq.

Nos três Editais Universais (01/2002, 019/2004 e 02/2006), 809 propostas foram enviadas ao Programa Básico de Zootecnia e 168 foram aprovadas (20,8\% de aprovação) (Tabela 2). Na evolução geral da demanda bruta, houve

Tabela 1 - Características dos Editais Universais 01/2002, 019/2004 e 02/2006

\begin{tabular}{cccc}
\hline Edital Universal & $01 / 2002$ & $019 / 2004$ & $02 / 2006$ \\
\hline Faixa de valores, R\$ & & & \\
A & Até $20.000,00$ & Sem faixas: & Sem faixas: \\
B & $20.001,00$ a $50.000,00$ & Até $50.000,00$ & Até $50.000,00^{1}$ \\
C & $50.001,00$ a $100.000,00$ & &
\end{tabular}

Recursos por faixa, R\$

A
B
C

Corte no orçamento pelo Comitê Assessor?

Reserva para as Regiões Norte, Nordeste e Centro-Oeste?

$$
\begin{gathered}
\text { 7.500.000,00 } \\
10.500 .000,00 \\
12.000 .000,00 \\
\text { Não } \\
\text { Não }
\end{gathered}
$$

$42.000 .000,00$

Sem restrições

Não
$90.000 .000,00^{2}$

Até $30 \%$ Mínimo de 30\%

\footnotetext{
1 Para os projetos relacionados à cadeia de conhecimento do Petróleo e Gás Natural, originários das regiões Norte, Nordeste e Centro-Oeste, foi possíve pleitear até $\mathrm{R} \$ 200.000,00$ (duzentos mil reais), uma vez que as propostas foram custeadas com recursos do CT-Petro no Edital $02 / 2006$.

2 O valor global estimado para o financiamento das propostas aprovadas foi de $R \$ 90.000 .000,00$ (noventa milhões de reais), dos quais $R \$ 70.000 .000,00$ (setenta milhões de reais) foram provenientes do orçamento do CNPq e R $\$ 20.000 .000,00$ (vinte milhões de reais) dos Fundos Setoriais do Petróleo e Gás Natural (CT-Petro), Recursos Hídricos (CT-Hidro), Tecnologia de Informação (CT-Info), Aquaviário (CT-Aquaviário) e Mineral (CT-Mineral), nos exercícios de 2006 e 2007.
} 
Tabela 2 - Total de propostas enviadas (demanda bruta) e de propostas favoráveis (demanda atendida) no Programa Básico de Zootecnia nos três Editais Universais

\begin{tabular}{|c|c|c|c|c|}
\hline Subáreas do conhecimento & Total ( $(\mathrm{n} \underline{0})$ & Aprovada $\left(\mathrm{n}^{\mathrm{o}}\right)$ & Total $(\%)^{1}$ & FV $(\%)^{1}$ \\
\hline & \multicolumn{4}{|c|}{ Edital Universal 01/2002 } \\
\hline Nutrição e alimentação animal & 74 & 9 & 39,2 & 33,3 \\
\hline Pastagem e forragicultura & 41 & 2 & 21,7 & 7,4 \\
\hline Produção animal & 39 & 6 & 20,6 & 22,2 \\
\hline Ecologia dos animais domésticos e etologia & 9 & 4 & 4,8 & 14,8 \\
\hline Genética e melhoramento dos animais domésticos & 26 & 6 & 13,8 & 22,2 \\
\hline \multirow[t]{2}{*}{ Total Edital 01/2002 } & 189 & 27 & - & 14,3 \\
\hline & \multicolumn{4}{|c|}{ Edital Universal 019/2004 } \\
\hline Nutrição e alimentação animal & 117 & 46 & 38,0 & 50,0 \\
\hline Pastagem e forragicultura & 68 & 14 & 22,1 & 15,2 \\
\hline Produção animal & 70 & 16 & 22,7 & 17,4 \\
\hline Ecologia dos animais domésticos e etologia & 11 & 0 & 3,6 & 0,0 \\
\hline Genética e melhoramento dos animais domésticos & 42 & 16 & 13,6 & 17,4 \\
\hline \multirow[t]{2}{*}{ Total Edital 019/2004 } & 308 & 92 & - & 29,9 \\
\hline & \multicolumn{4}{|c|}{ Edital Universal 02/2006 } \\
\hline Nutrição e alimentação animal & 112 & 23 & 35,9 & 46,9 \\
\hline Pastagem e forragicultura & 67 & 9 & 21,5 & 18,4 \\
\hline Produção animal & 82 & 9 & 26,3 & 18,4 \\
\hline Ecologia dos animais domésticos e etologia & 6 & 0 & 1,9 & 0,0 \\
\hline Genética e melhoramento dos animais domésticos & 45 & 8 & 14,4 & 16,3 \\
\hline Total Edital 02/2006 & 312 & 49 & - & 12,8 \\
\hline Total Geral & 809 & 168 & - & 20,8 \\
\hline
\end{tabular}

${ }^{1}$ Valores obtidos dividindo-se o número total de propostas apresentadas e aprovadas em cada subárea do conhecimento pelo número total de propostas apresentadas e aprovadas em todo o Programa Básico de Zootecnia em cada Edital Universal, respectivamente, multiplicados por 100.

aumento significativo do número de projetos submetidos ao Programa Básico de Zootecnia, que passou de 189 em 2002 para 312 propostas em 2006. Tanto em 2002 quanto em 2006, apenas 12,8 e $14,3 \%$ dos projetos submetidos foram aprovados e financiados pelo CNPq. No entanto, em 2004, a porcentagem de projetos aprovados dobrou, passando para 29,9\%, como resultado do apoio financeiro adicional (R\$ 500.000,00) do Fundo Setorial do Agronegócio para fomentar projetos de pesquisas meritórios e que contribuíssem para o desenvolvimento do agronegócio brasileiro, no âmbito da Coordenação do Programa de Pesquisa em Agropecuária e Agronegócio - COAGR.

Nos três Editais Universais, Nutrição e Alimentação Animal foi a subárea com maior número de propostas e representou 37,5\% da demanda bruta (Tabela 2) e um total solicitado de R\$11,3 milhões (Tabela 3). Em seguida, Produção Animal e Pastagem e Forragicultura foram as subáreas com 23,6 e 21,8\% do número de propostas e R\$ 7,5 e 7,1 milhões solicitados, respectivamente. De modo geral, apenas pequenas variações ocorreram no número relativo de propostas nas diferentes subáreas do conhecimento nos três Editais Universais, o que evidencia estabilidade das subáreas. Entretanto, a subárea Nutrição e Alimentação Animal apresentou ao longo do período ligeira redução no número relativo de projetos, que diminuiu de
39,2\% em 2002 para 35,9\% em 2006, porém, houve aumento na quantidade de recursos solicitados ( $\mathrm{R}$ \$ 2,8 milhões em 2002 para $\mathrm{R}$ \$ 4,4 milhões em 2006). A mesma redução no número de propostas se repetiu para a subárea Ecologia dos Animais Domésticos e Etologia (de 4,8 para 1,9\%), mas neste caso a quantidade de recursos demandados também reduziu. Pastagem e Forragicultura e Genética e Melhoramento dos Animais Domésticos permaneceram estáveis, enquanto a demanda da subárea Produção Animal passou de 20,6 para 24,6\% em relação ao total da área no período estudado. Todas as subáreas apresentaram crescimento nos valores solicitados.

A subárea Nutrição e Alimentação Animal foi a que teve maior número de propostas aprovadas nos três Editais Universais, totalizando 78 das 168 (46,4\% das propostas aprovadas) (Tabela 2). Em seguida, Produção Animal, Genética e Melhoramento dos Animais Domésticos e Pastagem e Forragicultura tiveram número semelhante de propostas aprovadas: 31,30 e 25 , que representam 18,5; 17,8 e 14,9\% das propostas aprovadas, respectivamente. Ecologia dos Animais Domésticos e Etologia foi a subárea com menor número de propostas enviadas e aprovadas e não teve nenhum aporte de recursos nos anos de 2004 e 2006 (Tabela 3), evidenciando que, possivelmente, as pesquisas nessa subárea não são priorizadas pela comunidade científica de Zootecnia. 
Uma das prováveis razões é que, enquanto as outras três subáreas estão significativamente relacionadas a ganhos comerciais decorrentes dos resultados das pesquisas, Ecologia dos animais domésticos e etologia caracteriza-se por estudos mais acadêmicos que não promovem diretamente, e a curto prazo, aumentos de produtividade. Dessa forma, a característica pragmática dos programas de Zootecnia tem feito que estudos desta natureza sejam secundarizados.

A Região Sudeste foi aquela com maior demanda bruta nos três Editais, com 378 projetos enviados (aproximadamente 46,7 do total) (Tabela 4). Somente a Região Sudeste solicitou R \$14,2 milhões no período, enquanto o montante

Tabela 3 - Recursos financeiros solicitados (demanda bruta) e aprovados (demanda atendida) no Programa Básico de Zootecnia nos três Editais Universais

\begin{tabular}{|c|c|c|c|c|}
\hline & \multicolumn{3}{|c|}{ Edital Universal } & Total geral \\
\hline Subárea do conhecimento & \multicolumn{4}{|c|}{ Recursos solicitados } \\
\hline Nutrição e alimentação animal & $2.763 .875,36$ & $4.118 .915,15$ & 4.383.115,14 & $11.265 .905,65$ \\
\hline Pastagem e forragicultura & $1.869 .116,29$ & $2.581 .324,21$ & $2.612 .190,09$ & $7.062 .630,59$ \\
\hline Produção animal & $1.594 .258,01$ & $2.603 .190,94$ & $3.278 .922,55$ & $7.476 .371,50$ \\
\hline \multirow[t]{2}{*}{ Total solicitado } & $7.653 .728,46$ & $11.072 .417,24$ & $12.193 .102,40$ & $30.919 .248,10$ \\
\hline & \multicolumn{4}{|c|}{ Recursos aprovados } \\
\hline Nutrição e alimentação animal & $384.750,84$ & $1.249 .074,37$ & $742.023,80$ & $2.375 .849,01$ \\
\hline Pastagem e forragicultura & $53.655,36$ & $489.054,24$ & $267.347,96$ & $810.057,56$ \\
\hline Produção animal & $242.101,13$ & $440.226,94$ & $280.335,75$ & $962.663,82$ \\
\hline
\end{tabular}

Tabela 4 - Total de propostas enviadas (demanda bruta) ao Programa Básico de Zootecnia nos três Editais Universais

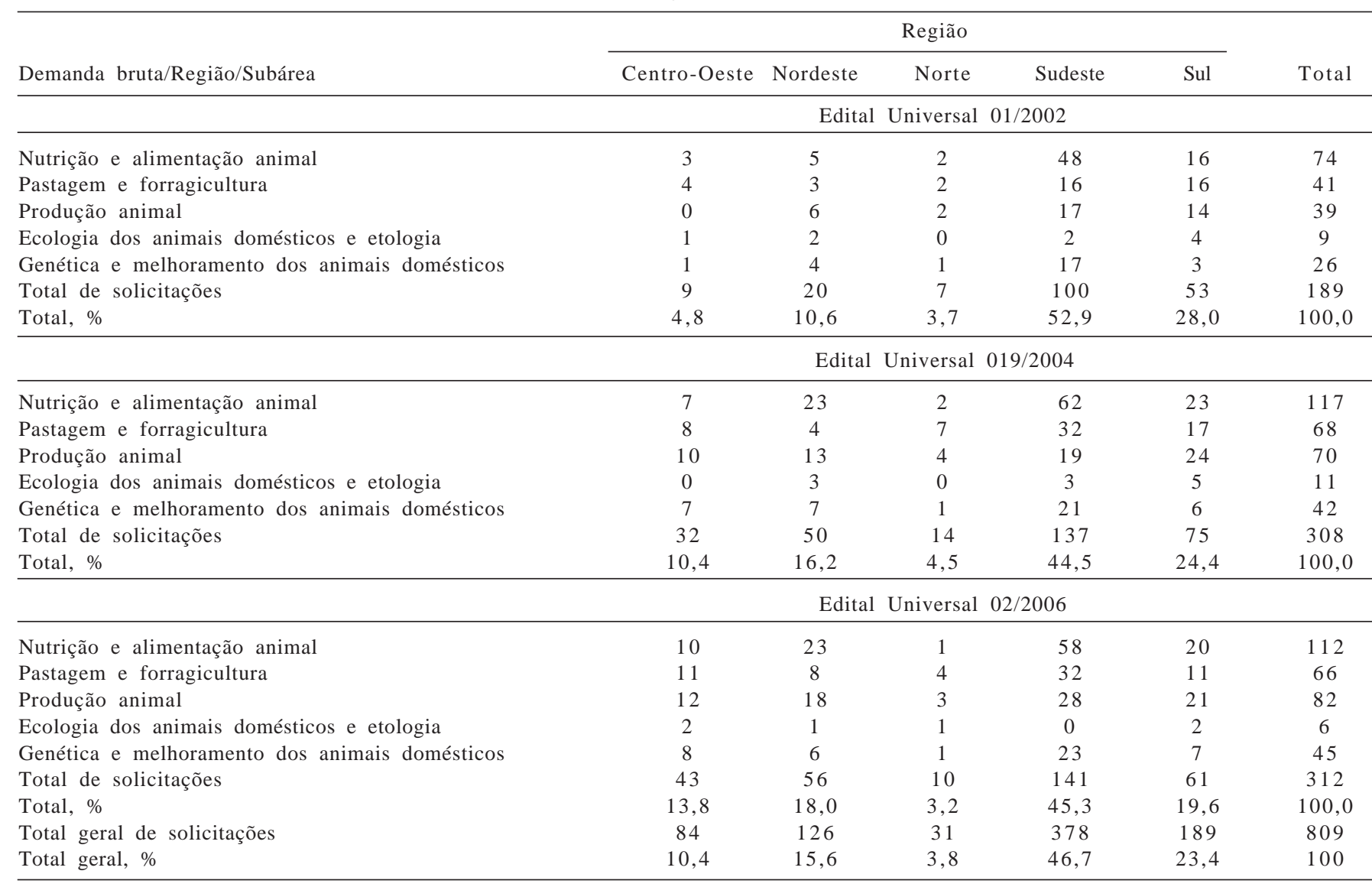


de recursos solicitados nacionalmente totalizou $\mathrm{R} \$ 30,9$ milhões (Tabela 5). A segunda região com maior número de propostas, somando-se os três Editais, foi a Região Sul, com 189 propostas, que representaram 18,4\% do total e exatamente $50 \%$ do apresentado pela Região Sudeste. Ressalta-se que o número de propostas apresentadas pela Região Sul em relação às demais diminuiu quase linearmente de 2002 para 2006, passando de 28,0 para 19,6\%.

A região com menor número de propostas foi a Norte, representando em valores médios 3,8\% do total geral, provavelmente em virtude do baixo número de pesquisadores com título de doutor e infra-estrutura disponível para realização desses estudos. As regiões Centro-Oeste e Nordeste apresentaram valores médios intermediários de demanda bruta (10,4 e $15,6 \%$ do total). No entanto, os valores de demanda bruta dessas duas regiões foram crescentes nos últimos três Editais, uma vez que a Região Centro-Oeste passou de 4,8\% em 2002 para 13,8\% em 2006 e a Região Nordeste, de 10,6\% em 2002 para 18,0\% em 2006.

A Região Sudeste foi a mais atendida, uma vez que apresentou também a maior demanda. Em seguida, as regiões Sul e Nordeste alternaram na segunda classificação, considerando os três Editais (Tabela 5).

A política de desenvolvimento regional do CNPq parece ter apresentado resultados satisfatórios, uma vez que em 2006 a porcentagem mínima de aprovação para as regiões Norte, Nordeste e Centro-Oeste, somadas, atingiram 30,6\%, invertendo a tendência de redução observada em 2004 (10,8\%). No entanto, enquanto a Região CentroOeste apresentou aumento relativo no número de propostas atendidas e a Nordeste recuperou em relação a 2004 e 2002, apenas um projeto da Região Norte foi aprovado em 2002, fato que não se repetiu nos Editais subseqüentes (Tabela 6). Esses valores parecem indicar o crescente desenvolvimento da área de zootecnia da Região Centro-Oeste nos últimos anos e a atual capacidade de infra-estrutura e de pesquisadores qualificados na Região Nordeste. No outro extremo, a Região Norte, cuja capacidade de formulação de propostas e obtenção de investimentos na área ainda é baixa, apesar da importância da pesquisa na região e da crescente incorporação de suas áreas no processo produtivo, o que parece estar acontecendo sem adequado acompanhamento técnico-científico.

Para melhor avaliação do atendimento regional, foram criados pela Coordenação (COAGR) dois diferentes índices: Índice Regional de Aprovação (IRA), obtido pela divisão do número de projetos aprovados na região pelo número de projetos submetidos nessa mesma região; e Índice Nacional de Aprovação (INA), obtido pela divisão do número de projetos aprovados nacionalmente pelo número de projetos submetidos nacionalmente (Tabela 7). Se o IRA $\cong$ INA, a aprovação regional está próxima à aprovação média nacional, no entanto, se o IRA for diferente do INA para mais ou para menos, a aprovação de projetos naquela Região está acima ou abaixo da aprovação média nacional para determinado edital ou período avaliado.

Considerando a média das aprovações no período de 2002 a 2006 (Tabela 7), a Região Sudeste foi a única com o IRA ligeiramente maior que o INA, logo, nesse período, a aprovação para essa região foi mais que proporcional à submissão em comparação às demais regiões. No entanto, as regiões Sul e Nordeste apresentaram o IRA próximo (apesar de menor) ao INA, o que indica certo equilíbrio entre submissão e aprovação comparativas.

Tabela 5 - Recursos financeiros solicitados (demanda bruta) e aprovados (demanda atendida) no Programa Básico de Zootecnia nos três Editais Universais

\begin{tabular}{|c|c|c|c|c|}
\hline & & Edital Universal & & \\
\hline & $01 / 2002$ & $019 / 2004$ & $02 / 2006$ & Total geral \\
\hline Região & & & itados & \\
\hline Centro-Oeste & $401.937,70$ & $1.121 .471,95$ & $1.770 .863,75$ & $3.294 .273,40$ \\
\hline Nordeste & $900.000,58$ & $1.720 .214,67$ & $2.138 .955,76$ & $4.759 .171,01$ \\
\hline Norte & $420.365,81$ & $552.830,91$ & $437.505,54$ & $1.410 .702,26$ \\
\hline Sudeste & $3.748 .458,42$ & $4.910 .530,51$ & $5.581 .844,42$ & $14.240 .833,35$ \\
\hline Sul & $2.182 .965,95$ & $2.767 .369,20$ & $2.263 .932,93$ & $7.214 .268,08$ \\
\hline Total solicitado & $7.653 .728,46$ & $11.072 .417,24$ & $12.193 .102,40$ & $30.919 .248,10$ \\
\hline & & & vados & \\
\hline Centro-Oeste & $18.818,56$ & $120.340,00$ & $140.456,51$ & $279.615,07$ \\
\hline Nordeste & $206.359,88$ & $107.588,25$ & $276.944,83$ & $590.892,96$ \\
\hline Norte & $39.250,50$ & 0,00 & 0,00 & $39.250,50$ \\
\hline Sudeste & $541.773,49$ & $1.770 .313,18$ & $840.193,53$ & $3.152 .280,20$ \\
\hline Sul & $195.309,37$ & $555.167,72$ & $277.319,41$ & $1.027 .796,50$ \\
\hline Total aprovado & $1.001 .511,80$ & $2.553 .409,15$ & $1.534 .914,28$ & $5.089 .835,23$ \\
\hline
\end{tabular}


Tabela 6 - Total de propostas favoráveis (demanda atendida) no Programa Básico de Zootecnia nos três Editais Universais

\begin{tabular}{|c|c|c|c|c|c|c|}
\hline \multirow[b]{2}{*}{ Demanda atendida/Região/Subárea } & \multicolumn{5}{|c|}{ Região } & \multirow[b]{2}{*}{ Total } \\
\hline & Centro-Oeste & Nordeste & Norte & Sudeste & Sul & \\
\hline \multicolumn{7}{|c|}{ EU $01 / 2002$} \\
\hline Nutrição e alimentação animal & 0 & 0 & 1 & 7 & 1 & 9 \\
\hline Pastagem e forragicultura & 1 & 1 & 0 & 0 & 0 & 2 \\
\hline Produção animal & 0 & 1 & 0 & 3 & 2 & 6 \\
\hline Ecologia dos animais domésticos e etologia & 0 & 2 & 0 & 1 & 1 & 4 \\
\hline Genética e melhoramento dos animais domésticos & 0 & 1 & 0 & 4 & 1 & 6 \\
\hline Total da demanda atendida & 1 & 5 & 1 & 15 & 5 & 27 \\
\hline Total, \% & 3,7 & 18,5 & 3,7 & 55,6 & 18,5 & 14,3 \\
\hline \multicolumn{7}{|c|}{ EU $019 / 2004$} \\
\hline Nutrição e alimentação animal & 2 & 5 & 0 & 32 & 7 & 46 \\
\hline Pastagem e forragicultura & 1 & 0 & 0 & 8 & 5 & 14 \\
\hline Produção animal & 1 & 0 & 0 & 10 & 5 & 16 \\
\hline Ecologia dos animais domésticos e etologia & 0 & 0 & 0 & 0 & 0 & 0 \\
\hline Genética e melhoramento dos animais domésticos & 1 & 0 & 0 & 12 & 3 & 16 \\
\hline Total da demanda atendida & 5 & 5 & 0 & 62 & 20 & 92 \\
\hline Total, \% & 5,4 & 5,4 & 0,0 & 67,4 & 21,7 & 29,9 \\
\hline \multicolumn{7}{|c|}{ EU $02 / 2006$} \\
\hline Nutrição e alimentação animal & 1 & 6 & 0 & 13 & 3 & 23 \\
\hline Pastagem e forragicultura & 1 & 2 & 0 & 3 & 3 & 9 \\
\hline Produção animal & 1 & 2 & 0 & 3 & 3 & 9 \\
\hline Ecologia dos animais domésticos e etologia & 0 & 0 & 0 & 0 & 0 & 0 \\
\hline Genética e melhoramento dos animais domésticos & 1 & 1 & 0 & 6 & 0 & 8 \\
\hline Total da demanda atendida & 4 & 11 & 0 & 25 & 9 & 49 \\
\hline Total, \% & 8,2 & 22,4 & 0,0 & 51,0 & 18,4 & 12,8 \\
\hline
\end{tabular}

Tabela 7 - Valores do Índice Regional de Aprovações (IRA) e do Índice Nacional de Aprovação (INA) nos Editais Universais de 2002 a 2006

\begin{tabular}{|c|c|c|c|c|c|c|}
\hline \multirow{2}{*}{$\begin{array}{l}\text { Índice/Região } \\
\text { Subárea }\end{array}$} & \multicolumn{5}{|c|}{ IRA } & \multirow[t]{2}{*}{ INA } \\
\hline & Centro-Oeste & Nordeste & Norte & Sudeste & Sul & \\
\hline Nutrição e alimentação animal & 0,150 & 0,216 & 0,200 & 0,310 & 0,186 & 0,257 \\
\hline Pastagem e forragicultura & 0,130 & 0,200 & 0 & 0,139 & 0,186 & 0,145 \\
\hline Produção animal & 0,091 & 0,081 & 0 & 0,250 & 0,169 & 0,162 \\
\hline Ecologia dos animais domésticos e etologia & 0 & 0,333 & 0 & 0,200 & 0,091 & 0,154 \\
\hline Genética e melhoramento dos animais domésticos & 0,125 & 0,118 & 0 & 0,361 & 0,250 & 0,265 \\
\hline Total & 0,119 & 0,167 & 0,032 & 0,271 & 0,181 & 0,208 \\
\hline
\end{tabular}

O mérito das propostas da Região Centro-Oeste e notadamente da Região Norte parece estar abaixo do mérito das demais Regiões, portanto, são necessárias ações complementares de fomento.

\section{Conclusões}

Os recursos do CNPq voltados para ciência, tecnologia e inovação (C,T\&I) têm aumentado no País, tanto para infra-estrutura (ampliação, melhoria e construção de novas instalações) quanto para disponibilização de auxílios à pesquisa e bolsas, o que aumenta quali e quantitativamente a base de pesquisadores. O CNPq tem estimulado a publicidade de suas ações visando permitir ao pesquisador conhecer a política de investimento e a forma de trabalho desta agência e entender como seu projeto de pesquisa é avaliado. Seguindo uma política nacional, o CNPq tem melhorado e ampliado seus programas e processos de fomento, acompanhando junto com a comunidade científica e tecnológica as novas demandas e os desafios da evolução.

\section{Agradecimento}

À Coordenação de Suporte ao Fomento - COSFO/ CNPq, pela disponibilização dos dados referentes aos Editais Universais estudados. 


\section{Literatura Citada}

KING, D.A. The scientific impact of nations: what different countries get for their research spending. Nature, v.430, n.6997, p.311-316, 2004.

KUPPERMANN, A. Investimentos em Ciência e Tecnologia. Estudos Avançados, v.8, n.20, p.18-22, 1994.
MINISTÉRIO da Ciência e Tecnologia. [2005]. Investimentos nacionais em Ciência \& Tecnologia. Disponível em: <http:// ftp.mct.gov.br/estat/ascavpp/gti_web/abertura.htm>. Data de acesso: 20/9/2007.

MINISTÉRIO da Ciência e Tecnologia. Relatório de Gestão: janeiro de 2003 a dezembro de 2006, 2006. Disponível em: <http://www.mct.gov.br/index.php/content/view/56946.html>. Data de acesso: 20/9/2007. 